\title{
The posterior cranial fossa's dura mater innervation and its clinical implication in headache: a comprehensive review
}

\author{
D. Hage ${ }^{1}$, M. Mathkour ${ }^{1}$, J. Iwanaga ${ }^{1,2}$, A.S. Dumont ${ }^{1}$, R.S. Tubbs ${ }^{1-5}$ \\ ${ }^{1}$ Department of Neurosurgery, Tulane Centre for Clinical Neurosciences, Tulane University School of Medicine, \\ New Orleans, LA, United States \\ 2Department of Neurology, Tulane Centre for Clinical Neurosciences, Tulane University School of Medicine, \\ New Orleans, LA, United States \\ ${ }^{3}$ Department of Neurosurgery and Ochsner Neuroscience Institute, Ochsner Health System, New Orleans, LA, \\ United States \\ ${ }^{4}$ Department of Anatomical Sciences, St. George's University, St. George's, Grenada \\ ${ }^{5}$ Department of Structural and Cellular Biology, Tulane University School of Medicine, New Orleans, LA, United States
}

[Received: 9 April 2021; Accepted: 9 July 2021; Early publication date: 28 October 2021]

\begin{abstract}
The pathophysiology of migraines and headaches has been a point of interest in research as they affect a large subset of the population, and the exact mechanism is still unclear. There is evidence implicating the dura mater and its innervation as contributing factors, especially at the posterior cranial fossa. Many modes of innervation have been identified, including the dorsal root ganglion, superior cervical ganglion, vagus nerve, trigeminal nerve, hypoglossal nerve, and glossopharyngeal nerve. While the exact method of innervation is still under investigation, there is strong evidence suggesting that different types of headaches (migraine vs. occipital vs. cervicogenic) are due to specific nerves and inflammatory mediators that contribute to the dura mater in some way. By understanding how these innervation patterns manifest clinically, the course of treatment can be tailored based on the physiological aetiology. Here, we present a comprehensive literature review of the current research regarding the innervation of the dura mater of the posterior cranial fossa and its clinical implications. (Folia Morphol 2022; 81, 4: 843-850)
\end{abstract}

Key words: anatomy, nerves, cranium, meninges, headache

\section{INTRODUCTION}

The dura mater is the most superficial constituent of the cranial meninges and acts as a protective covering for the brain [1, 33]. It is composed of an inner meningeal and an outer endosteal layer [1, 33]. The outer endosteal layer is occupied by nerves and blood vessels and forms the skull's periosteum, which can be further divided into an outer fibrous layer and an inner layer with osteoblastic potential [1, 17, 33]. The cranial dura mater's inner meningeal layer has com- munication with the dura mater of the spinal cord at the foramen magnum and forms the falx cerebri, falx cerebelli, tentorium cerebelli, and diaphragma sella $[1,33]$. The dural venous sinuses can be identified along with various positions of dura mater reflection between the two layers [1, 23, 50,61]. The innervation of the dura mater has been a point of interest in research due to its clinical implications with various types of headaches $[5,10,34,43,48,52,55,60$, 84]. This article reviews the literature regarding the

Address for correspondence: Dr. J. Iwanaga, Department of Neurosurgery, Tulane Centre for Clinical Neurosciences, Tulane University School of Medicine, 131 S. Robertson St. Suite 1300, New Orleans, LA 70112, USA, tel: 5049885565, fax: 5049885793, e-mail: iwanagajoeca@gmail.com This article is available in open access under Creative Common Attribution-Non-Commercial-No Derivatives 4.0 International (CC BY-NC-ND 4.0) license, allowing to download articles and share them with others as long as they credit the authors and the publisher, but without permission to change them in any way or use them commercially. 
innervation of the dura mater of the posterior cranial fossa, and its associated clinical relevance.

\section{THE POSTERIOR CRANIAL FOSSA}

The posterior cranial fossa is the largest and deepest fossa within the skull $[6,26,76]$. It serves as a conduit for several cranial nerves and contains important structures such as the brain stem, cerebellum, and foramen magnum $[6,26,76]$. Abnormalities (e.g., hypoplasia) of the posterior cranial fossa are often seen in patients with Chiari and other cerebellar malformations [76].

\section{Dorsal root ganglia and superior cervical ganglia}

In a study of 54 Sprague-Dawley rats, Noseda et al. [51] utilised a green fluorescent protein labelled adeno-associated viral vector to map the innervation of the dura mater of the posterior cranial fossa. The results demonstrated that the dura mater of the posterior cranial fossa receives innervation from axons of sensory neurons in the $\mathrm{C} 2$ and $\mathrm{C} 3$ dorsal root ganglion (DRG) [51]. The axons were observed to gain entry into the cranium through various routes including the foramen magnum, the jugular foramen, and various bony canals (occipital-periotic, emissary, and hypoglossal) within the occipital bone (Fig. 1) [51]. Furthermore, it was noted that the $\mathrm{C} 2-\mathrm{C} 4$ segments of the spinal cord contain the dorsal horn neurons responsible for transmitting nociceptive information from the posterior/occipital dura mater [51].

Keller et al. [32] utilised horseradish peroxidase labelling to examine the innervation of the dura mater of the posterior cranial fossa in cats [33]. After completing nerve resections, they observed a bilateral distribution of labelled cells in both the superior cervical ganglion and C1-C3 of the DRG [32,33]. Therefore, they concluded that these provided the majority of the innervation to the posterior cranial fossa $[32,33]$. Additionally, they noted the presence of some labelled cells within the trigeminal ganglion and the superior ganglion of the vagus nerve, leading them to suspect some innervation involvement from the trigeminal and vagus nerves (Fig. 2) [32, 33].

In an examination of 22 human foetuses, Kimmel et al. [36] observed that the innervation of the dura mater of the posterior cranial fossa was provided by the superior cervical ganglion and $\mathrm{C} 1-\mathrm{C} 3$ of the DRG [33]. They noted that the meningeal branches of $\mathrm{C} 1-\mathrm{C} 3$ of the DRG utilise the foramen magnum to enter the cranium and provide innervation to the

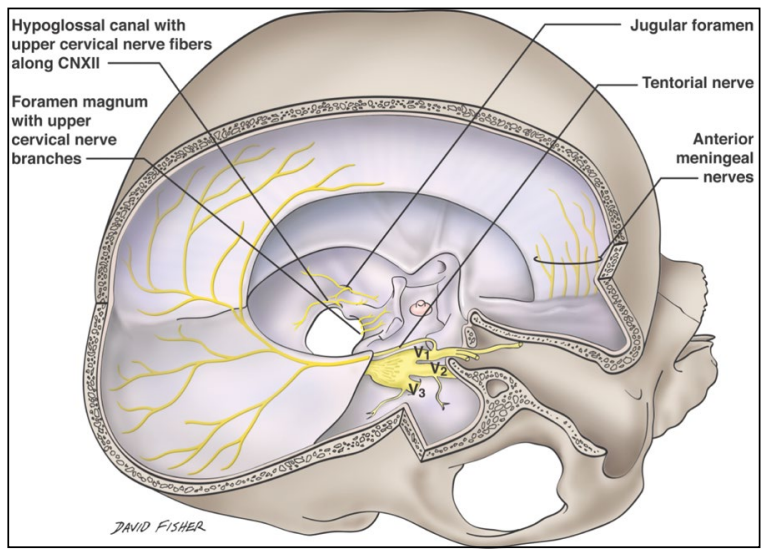

Figure 1. Schematic drawing of the skull base and illustrating entrance sites of meningeal nerves supplying the posterior cranial fossa such as the hypoglossal canal, foramen magnum and jugular foramen. Also, note the innervation of the tentorium cerebelli from primarily the tentorial nerve derived from $\mathrm{V} 1$ of the trigeminal nerve.

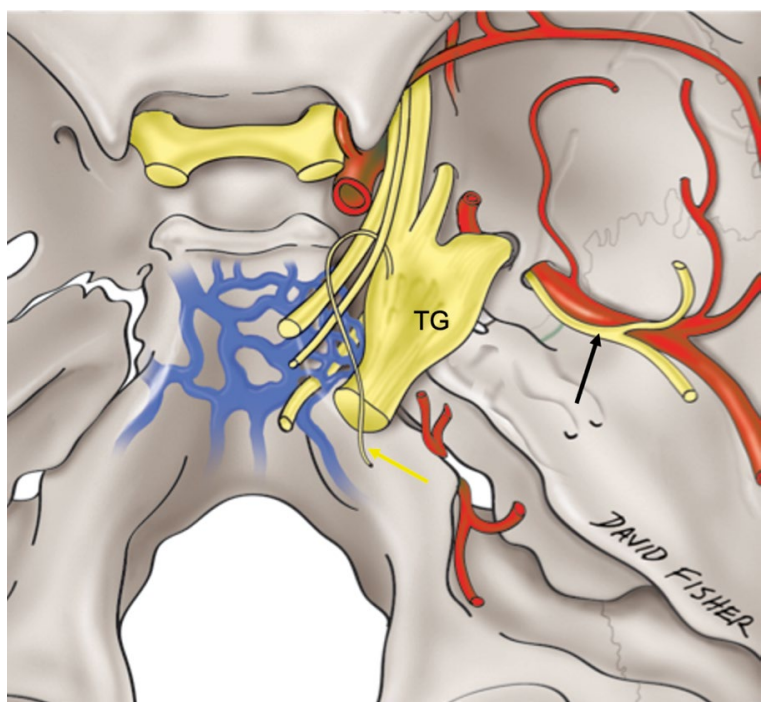

Figure 2. Schematic drawing of the skull base noting the tentorial nerve (yellow arrow) arising from the V1 part of the trigeminal nerve. Regionally, also note the nervus spinosus branch (black arrow) of V3 entering the foramen ovale with the middle meningeal artery (unlabelled); TG — trigeminal ganglion.

anterior portion of the posterior cranial fossa [33, 36]. In contrast, the superior cervical ganglion and C1-C2 of the DRG utilise the hypoglossal canal and the jugular foramen to access and innervate the lateral and posterior portions of the posterior cranial fossa $[33,36]$. These nerves may also use the vagus and hypoglossal nerves for access to the posterior cranial fossa $[33,36]$.

Likewise, studies by Bogduk et al. [9] have reported that the $\mathrm{C} 3$ cervical sinuvertebral nerve (SVN) 
innervates the dura mater of the posterior cranial fossa and follows a prolonged course through the posterior cranial fossa and the vertebral canal. Based on these results, Rennie et al. [68] were able to trace the intraspinal courses of all three SVNs. They found that smaller branches off the ascending and descending branches provide innervation to the dura mater, adjacent joints, surrounding ligaments, and soft tissues [68]. They observed that the SVNs were initially formed within the intervertebral foramen, then gave off branches that ran anterior to the DRG within the epidural space [68]. In concurrence with Kimmel at al. [36], they reported that the $\mathrm{C} 1-\mathrm{C} 2$ and $\mathrm{C} 2-\mathrm{C} 3$ levels had long ascending branches that supplied innervation to structures within the vertebral canal and the posterior cranial fossa [68]. Additionally, communication was found between the ascending branch of the C2 SVN and the hypoglossal nerve, confirming the presence of sensory interaction between cervical and cranial nerves [68]. This was further supported through foetal studies that identified a similar communication loop between the $\mathrm{C} 2-\mathrm{C} 3$ ascending branches and an extradural nerve that emerges from the hypoglossal canal $[33,36,68]$.

\section{Cranial nerves}

Penfield and McNaughton observed innervation contributions from the hypoglossal nerve and the vagus nerve's recurrent branches traveling alongside the posterior meningeal artery [62]. The vagus nerve's recurrent branches were identified coursing to the falx cerebelli and the inferior wall of the transverse sinus [62]. Additionally, Levy and Strassman [40] noted the presence of unmyelinated C- and thinly myelinated $A \delta$-fibres from the trigeminal nerve within the dura mater. Both of these are consistent with the suspicions of Keller et al. [32] who predicted some vagus and trigeminal nerve involvement with the innervation of the dura mater of the posterior cranial fossa and Schueler et al. [73] who identified meningeal nerve fibres within the dura mater stemming from the trigeminal ganglion.

Kimmel et al. [36] identified branches of the hypoglossal nerve traveling superiorly from the hypoglossal canal to supply the dura mater of the posterior cranial fossa [33]. Kemp et al. [33] has also reported that branches of the facial and glossopharyngeal nerves contribute innervation to the dura mater of the posterior cranial fossa. These studies suggest that there is some cranial nerve innervation component to the dura mater overlying the posterior cranial fossa.

\section{CLINICAL RELEVANCE}

\section{Occipital headaches}

Occipital headaches have been reported to play a role in both migraine and non-migraine headaches [51]. While the debate regarding its aetiology is ongoing, evidence suggests that occipital headaches are caused by compression and irritation of the C2 DRG $[13,30,34]$. This idea is further supported in studies where the administration of anaesthetic blockade to the occipital nerve and its branches alleviated occipital pain and headaches $[19,51,58,60]$. As mentioned earlier, Noseda et al. [51] mapped the innervation of the dura mater of the posterior cranial fossa to the C2-C3 level of the DRG. They found that approximately $50 \%$ of the neurons involved contained calcitonin gene-related peptide (CGRP) and transient receptor potential cation channel subfamily V member 1 (TRPV1) [51]. They also observed that the C2-C4 division of the spinal cord contains the dorsal horn neurons responsible for transmitting nociceptive information from the posterior/occipital dura mater [51]. These neurons contain receptive fields that extend from the ears and occipital skin to the superficial and deep muscles of the neck, and the skin overlying the upper neck [51]. Upon administering pro-inflammatory mediators to the dura mater of the posterior cranial fossa, a correlation was identified between the neuronal responsiveness and stimulation of the occipital skin and neck muscles [51]. These findings demonstrate a direct connection between occipital headaches and the innervation of the dura mater overlying the posterior cranial fossa.

\section{Migraines}

Migraine headaches are the most common neurological disability worldwide and are ranked as the second leading cause of disability [5, 22]. Additionally, women are 2-3 times more likely to suffer from migraines than men [5, 22]. The cranial meninges and nociceptive signalling from the dura mater have long been considered as the site of origin for the pain attributed to migraines $[5,41,48,55,79,83$, 84]. While the exact pathophysiology of this disease and its sexual dimorphism remains unknown, there is evidence suggesting a correlation between the peripheral release of neuropeptides such as CGRP, substance $P$, neurokinin $A$, and prostaglandin E2 (PGE2) within the dura mater and the onset of a migraine attack $[4,5,11,12,14,15,18,20,31,35,38,52$, $54,57,77,83,84]$. 
The research on substance $P, P G E 2$, and neurokinin $A$ is less extensive than CGRP; however, there is a correlation between elevated levels of all three mediators and the onset of migraine attacks; in fact, elevated levels of PGE2 have been measured in the saliva of migraine patients $[14,15,18,52,57]$. The role of neurokinin $A$ is still unclear; however, there is an established relationship between histamine release from dural mast cells following elevated PGE2 and substance $P[14,15,18,52,57]$. There is also evidence trigeminal axons' excitation stimulates the release of the dural mast cells, further demonstrating the role of the trigeminal nerve with the innervation of the dura mater [15, 32, 54, 73].

Studies have found that when the dura mater is exposed to CGRP, a dilatory effect can be seen within the vasculature, which induces migraine symptoms at that location $[4,5]$. Similar dilation events have been reported along with the dura mater on the head's side, experiencing spontaneous migraine attacks $[5,35]$. Furthermore, elevated levels of CGRP have been found in the venous blood, saliva, and cerebrospinal fluid of patients undergoing a migraine attack $[5,20]$. There is also evidence that intravenous administration of CGRP can elicit an attack [5,38], whereas CGRP inhibitors have been successful in the treatment of migraines [5, 77]. Additionally, administrations of nitric oxide to the dura mater have been shown to elicit migraine attacks in both humans and rats $[5,54-56]$, as nitric oxide has been found to increase CGRP release $[5,11]$.

Even though the exact mechanism of peripheral CGRP signalling in migraine headaches is still under investigation, there is evidence implicating extracellular adenosine triphosphate (ATP) as a contributory factor [83]. Through the utilization of rat models, Yegutkin et al. [83] discovered that upon exposure to CGRP, ATP and adenosine diphosphate levels increased in both the meninges and trigeminal cells, whereas adenosine levels decreased in the trigeminal cells. The ATP signalling subsequently resulted in a substantial buildup of intracellular $\mathrm{Ca} 2+$ within neurons and glial cells [83]. Additionally, high levels of ATP were correlated to nociceptive spikes within the meningeal trigeminal nerve fibres, and ATP was found to have the most prominent and lasting effects when compared to other metabolites, due to ATP activation of ionotropic (P2X) and metabotropic (P2Y) purinergic receptors within these neurons [12, 83]. These findings are corroborated by previous studies that also noted significant ATP releases during migraine attacks, as a result of opened pannexin channels [31, 83].

Avona et al. [5] successfully applied a rat model to understand better the sexual dimorphism of migraine attacks related to CGRP signalling within the dura mater. They observed that only female rats produced a cutaneous periorbital hypersensitivity following the administration of CGRP $(0.1 \mathrm{pg}-3.8 \mathrm{ug})$ to the dura mater. In contrast, the males were only responsive if the dura mater was initially primed with interleukin-6 or brain-derived neurotrophic factor [5] Additionally, only female rats displayed priming to a subthreshold administration of dural CGRP $(0.1 \mathrm{pg})$ [5]. These findings give us an insight into the sexual dimorphism of the disease and demonstrate the connection between CGRP signalling in the dura mater and migraine headaches.

\section{Cervicogenic headaches}

Cervicogenic headaches are defined as pain in the head originating from a location other than the head - typically the cervical spine $[10,59]$. These are among the most common types of headaches affecting weightlifting athletes and are associated with patients who have sustained a whiplash injury $[59,75$, 78]. Studies by both Bogduk et al. [9, 10] and Biondi et al. [8] observed that the source of pain originates from the cervical spine and is mediated through the upper cervical nerves [69]. They found that the upper cervical nerves supply the dura mater of the posterior cranial fossa and the ligaments of the craniovertebral junction [8-10,69]. Additionally, it was noted that these nerves share the same root as the dorsal rami responsible for transmitting nociceptive information from the posterior head and neck region [10]. This provides us with a better understanding of how the upper three cervical nerves mediate pain from the ligaments, dura mater, and soft tissues of the posterior cranial fossa and upper cervical column and how symptoms may manifest clinically [8-10,69].

\section{Botulinum toxin}

Botulinum neurotoxin (BoNT) has become a popular treatment option for several headache disorders, especially migraines, due to its anti-nociceptive properties [42]. Several different serotypes are produced by Clostridium Botulinum, however, only serotypes $A$ and $B$ have been approved for clinical use [7, 21]. It exerts its effects by enzymatically cleaving the 
25 kDA synaptosomal-associated protein (SNAP-25), thus inhibiting the ability for neurotransmitter-containing vesicles to fuse with the cell membrane $[21,44,70]$. Through this mechanism, studies have demonstrated the inhibitory effect of BoNT on the release of neurotransmitters - substance P and CGRP - involved in the transmission of pain, neurogenic inflammation, and peripheral and central sensitization [16, 21, 28, 42, 66, 81]. Additionally, there is some evidence that administration of BoNT reduces the inflammatory response $[28,42,64]$.

\section{SURGICAL RELEVANCE}

Operative treatment of occipital and migraine headache has existed for centuries with an early focus employed on blood vessels by Al-Zahrawi (936 to 1013 AD) e.g., using caustic skull cauterisation to alleviate headache [2], vessel ligation (French barber-surgeon Ambroise Pare; 1510 to 1590) [3], arteriotomies, bloodletting (application of temples leeches by Thomas Willis (1621 to 1675) and Robert Whytt (1714 to 1766) and arterial compression by Mollendorff in 1867 [47]. Many of these concepts/ treatments were used and carried into the middle ages in Europe.

These concepts of vessel involvement in occipital and migraine headaches have also been revisited in modern times in 1976 by Greek neurosurgeon Alexander D. Rapidis [67], and more recently by Dr. Elliot Shevel [74] who is an oral and maxillofacial surgeon. Between 1904 and 1955, Alexander Rapidis [67] described sectioning of the trigeminal pathways for permanent facial analgesia and injection of alcohol into the Gasserian ganglion with successful results. In 1964, Bruce C. Martin and Phillip J. Fagan [45] published the first report on the surgical management of occipital neuralgia with satisfactory results by excising segments of the greater occipital nerve, lesser occipital nerve, third occipital nerve, and posterior auricular nerve with injection of alcohol into the area that was excised. Since then, the operative management of headache continues to evolve with theories on the extracranial course and nerve origin. Recently, Bahman Guyuron [24], in 2000, introduced the current concept of nerve irritation and compression at specific points across the skull and by adjacent structures. He further described the surgical treatment of trigger sites, which evolved since then to include open, endoscopic, and minimally invasive techniques for decompression, neurectomy, arterial ligation, and arterectomy, depending on the anatomical location and underlying pathophysiology with success rates ranging between $68 \%$ and $95 \%$ in pain improvement $[37,39,49,71]$.

Many anatomical studies have shown that nerves can be compressed by different surrounding tissues such as vessels, bone, muscle, fascia, and fascial bands [29]. However, only some of these tissues have been investigated. Guyuron et al. [25] evaluated nerves removed during migraine surgery by electron microscopy with proteomics and reported deregulation of the myelination process and axonal abnormality in patients with migraine headaches versus controls.

Additionally, Perry et al. [63] evaluated calvarial periosteum as a source of chronic migraine, demonstrating decreased expression of genes that suppress inflammation and increased expression of proinflammatory markers. The authors concluded that the trigeminovascular nociceptors that reach the periosteum are activated through intracranial meningeal nociceptors and/or extracranial nerves [63]. Such findings have been supported by human and animal data showing that pain and sensory nerve fibres cross the calvarial periosteum via cranial sutures and connect extracranial and intracranial axons $[72,73]$.

Weiner and Reed [82] introduced occipital nerve stimulation (ONS) in 1999, a promising treatment for patients with medically intractable and highly disabling chronic headache disorders [82]. The exact mechanisms by which ONS modulate pain are poorly understood; however, multiple sites of action within the central and peripheral nervous systems have been proposed, including the upper spinal segmental level, supraspinal levels, and peripheral nerve levels [27].

Direct effects of neurostimulation on peripheral nerve fibre excitability include an increase in electrical threshold, slowing of conduction velocity, and decrease in response probability have all been reported [46]. Additionally, a widely held theory of neurostimulation is the gate-control theory of pain have been described $[46,80]$. Regarding ONS efficacy, Popeney and Alo [65] used C1-C3 peripheral nerve stimulation for migraine headaches, with showed $85 \%$ of patients reported at least $50 \%$ reduction in headache frequency or severity after the ONS implantation. Oh et al. [53] used ONS in migraine headaches with $90 \%$ of the patients reporting more than $90 \%$ pain relief, and $10 \%$ of the patients reporting $75-90 \%$ pain relief at 1 month after implantation. ONS provided a better life for some patients, gave hope to many more, and 
suggested that different types of headaches are likely due to specific nerve involvement.

\section{CONCLUSIONS}

Although various modes of innervation have been identified, there is extensive evidence supporting the involvement of the dura mater and its innervation with the onset of many headaches. These findings are essential to consider when determining the best approaches for treating headaches, as the aetiology and innervation patterns may vary.

\section{Conflict of interest: None declared}

\section{REFERENCES}

1. Adeeb N, Mortazavi MM, Tubbs RS, et al. The cranial dura mater: a review of its history, embryology, and anatomy. Childs Nerv Syst. 2012; 28(6): 827-837, doi: 10.1007/ s00381-012-1744-6, indexed in Pubmed: 22526439.

2. Al-Zahrawi AZ. The father of surgery. ANZ J Surg. 2007; 77(A83).

3. Ambroise P. The Works of Ambrose Parey, Chyrurgeon to Henry II, Francis II, Charles IX, and Henry III, Kings of France. J Hindmarsh, London 1691.

4. Asghar MS, Hansen AE, Kapijimpanga $T$, et al. Dilation by CGRP of middle meningeal artery and reversal by sumatriptan in normal volunteers. Neurology. 2010; 75(17): 1520-1526, doi: 10.1212/WNL.0b013e3181f9626a, indexed in Pubmed: 20975053.

5. Avona A, Burgos-Vega C, Burton MD, et al. Dural calcitonin gene-related peptide produces female-specific responses in rodent migraine models. J Neurosci. 2019; 39(22): 4323-4331, doi: 10.1523/JNEUROSCI.0364-19.2019, indexed in Pubmed: 30962278.

6. Berge JK, Bergman RA. Variations in size and in symmetry of foramina of the human skull. Clin Anat. 2001; 14(6): 406-413, doi: 10.1002/ca.1075, indexed in Pubmed: 11754234.

7. Bigalke H. Botulinum toxin: application, safety, and limitations. Curr Top Microbiol Immunol. 2013; 364: 307-317, doi: 10.1007/978-3-642-33570-9_14, indexed in Pubmed: 23239359.

8. Biondi DM, Biondi DM, Biondi DM. Cervicogenic headache: mechanisms, evaluation, and treatment strategies. J Am Osteopath Assoc. 2000; 100(9 Suppl): S7-S14, indexed in Pubmed: 11070659.

9. Bogduk N, Windsor M, Inglis A. The innervation of the cervical intervertebral discs. Spine (Phila Pa 1976). 1988; 13(1): 2-8, doi: 10.1097/00007632-198801000-00002, indexed in Pubmed: 3381132.

10. Bogduk N. Cervicogenic headache: anatomic basis and pathophysiologic mechanisms. Curr Pain Headache Rep. 2001; 5(4): 382-386, doi: 10.1007/s11916-001-0029-7, indexed in Pubmed: 11403743.

11. Burgos-Vega CC, Quigley LD, Avona A, et al. Dural stimulation in rats causes brain-derived neurotrophic factor-dependent priming to subthreshold stimuli including a migraine trigger. Pain. 2016; 157(12): 2722-2730, doi: 10.1097/j. pain.0000000000000692, indexed in Pubmed: 27841839.

12. Burnstock G, Krügel U, Abbracchio MP, et al. Purinergic signalling: from normal behaviour to pathological brain function. Prog Neurobiol. 2011; 95(2): 229-274, doi: 10.1016/j. pneurobio.2011.08.006, indexed in Pubmed: 21907261.

13. Chouret EE. The greater occipital neuralgia headache. Headache. 1967; 7(1): 33-34, doi: 10.1111/j.15264610.1967.hed0701033.x, indexed in Pubmed: 6046095.

14. Dimitriadou V, Buzzi MG, Moskowitz MA, et al. Trigeminal sensory fiber stimulation induces morphological changes reflecting secretion in rat dura mater mast cells. Neuroscience. 1991; 44(1): 97-112, doi: 10.1016/03064522(91)90253-k, indexed in Pubmed: 1771000.

15. Dimitriadou V, Rouleau A, Tuong MDT, et al. Functional relationships between sensory nerve fibers and mast cells of dura mater in normal and inflammatory conditions. Neuroscience. 1997; 77(3): 829-839, doi: 10.1016/s03064522(96)00488-5.

16. Durham PL, Cady R, Cady R. Regulation of calcitonin gene-related peptide secretion from trigeminal nerve cells by botulinum toxin type $A$ : implications for migraine therapy. Headache. 2004; 44(1): 35-42, doi: 10.1111/j.15264610.2004.04007.x, indexed in Pubmed: 14979881.

17. Dwek JR. The periosteum: what is it, where is it, and what mimics it in its absence? Skeletal Radiol. 2010; 39(4): 319-323, doi: 10.1007/s00256-009-0849-9, indexed in Pubmed: 20049593.

18. Ebersberger A. Physiology of meningeal innervation: aspects and consequences of chemosensitivity of meningeal nociceptors. Microsc Res Tech. 2001; 53(2): 138-146, doi: 10.1002/jemt.1078, indexed in Pubmed: 11301489.

19. Edmeads J. The cervical spine and headache. Neurology. 1988; 38(12): 1874-1878, doi: 10.1212/wnl.38.12.1874, indexed in Pubmed: 3194065.

20. Edvinsson L, Goadsby PJ. Neuropeptides in Migraine and Cluster Headache. Cephalalgia. 1994; 14(5): 320-327, doi: 10.1046/j.1468-2982.1994.1405320.x.

21. Escher CM, Paracka L, Dressler D, et al. Botulinum toxin in the management of chronic migraine: clinical evidence and experience. Ther Adv Neurol Disord. 2017; 10(2): 127-135, doi: 10.1177/1756285616677005, indexed in Pubmed: 28382110.

22. GBD 2016 Disease and Injury Incidence and Prevalence Collaborators. Global, regional, and national incidence, prevalence, and years lived with disability for 328 diseases and injuries for 195 countries, 1990-2016: a systematic analysis for the Global Burden of Disease Study 2016. Lancet. 2017; 390(10100): 1211-1259, doi: 10.1016/ S0140-6736(17)32154-2, indexed in Pubmed: 28919117.

23. Greenberg RW, Lane EL, Cinnamon J, et al. The cranial meninges: anatomic considerations. Semin Ultrasound CT MR. 1994; 15(6): 454-465, doi: 10.1016/s08872171(05)80017-4, indexed in Pubmed: 7880562.

24. Guyuron B, Riazi H, Long T, et al. Use of a Doppler signal to confirm migraine headache trigger sites. Plast Reconstr Surg. 2015; 135(4): 1109-1112, doi: 10.1097/ PRS. 0000000000001102 , indexed in Pubmed: 25811575.

25. Guyuron B, Yohannes E, Miller R, et al. Electron microscopic and proteomic comparison of terminal branches of the 
trigeminal nerve in patients with and without migraine headaches. Plast Reconstr Surg. 2014; 134(5): 796e-805e, doi: 10.1097/PRS.0000000000000696, indexed in Pubmed: 25347655.

26. Hofmann E, Prescher A. The Clivus. Clinical Neuroradiology. 2012; 22(2): 123-139, doi: 10.1007/s00062-011-0083-4.

27. Ignelzi RJ, Nyquist JK. Excitability changes in peripheral nerve fibers after repetitive electrical stimulation. Implications in pain modulation. J Neurosurg. 1979; 51(6): 824-833, doi: 10.3171/jns.1979.51.6.0824, indexed in Pubmed: 315452.

28. Jabbari B. Botulinum neurotoxins in the treatment of refractory pain. Nat Clini Pract Neurol. 2008; 4(12): 676-685, doi: 10.1038/ncpneuro0948, indexed in Pubmed: 19043424.

29. Janis JE, Barker JC, Javadi C, et al. A review of current evidence in the surgical treatment of migraine headaches. Plast Reconstr Surg. 2014; 134(4 Suppl 2): 131S-141S, doi: 10.1097/ PRS.0000000000000661, indexed in Pubmed: 25254996.

30. Johnston MM, Jordan SE, Charles AC. Pain referral patterns of the $\mathrm{C} 1$ to $\mathrm{C} 3$ nerves: implications for headache disorders. Ann Neurol. 2013; 74(1): 145-148, doi: 10.1002/ ana.23869, indexed in Pubmed: 23424170.

31. Karatas H, Erdener SE, Gursoy-Ozdemir Y, et al. Spreading depression triggers headache by activating neuronal Pan 1 channels. Science. 2013; 339(6123): 1092-1095, doi: 10.1126/ science.1231897, indexed in Pubmed: 23449592.

32. Keller JT, Saunders MC, Beduk A, et al. Innervation of the posterior fossa dura of the cat. Brain Res Bull. 1985; 14(1): 97-102, doi: 10.1016/0361-9230(85)90181-9, indexed in Pubmed: 3872702.

33. Kemp WJ, Tubbs RS, Cohen-Gadol AA. The innervation of the cranial dura mater: neurosurgical case correlates and a review of the literature. World Neurosurg. 2012; 78(5): 505-510, doi: 10.1016/j.wneu.2011.10.045, indexed in Pubmed: 22120554.

34. Kerr RW. A mechanism to account for frontal headache in cases of posterior-fossa tumors. J Neurosurg. 1961; 18: 605-609, doi: 10.3171/jns.1961.18.5.0605, indexed in Pubmed: 13752671.

35. Khan S, Amin FM, Christensen CE, et al. Meningeal contribution to migraine pain: a magnetic resonance angiography study. Brain. 2019; 142(1): 93-102, doi: 10.1093/ brain/awy300, indexed in Pubmed: 30590467.

36. Kimmel DL. Innervation of spinal dura mater and dura mater of the posterior cranial fossa. Neurology. 1961; 11: 800-809, doi: 10.1212/wnl.11.9.800, indexed in Pubmed: 13756002.

37. Koehler PJ, Boes CJ. A history of non-drug treatment in headache, particularly migraine. Brain. 2010; 133(Pt 8): 2489-2500, doi: 10.1093/brain/awq170, indexed in Pubmed: 20639545.

38. Lassen LH, Haderslev PA, Jacobsen VB, et al. CGRP may play a causative role in migraine. Cephalalgia. 2002; 22(1): 54-61, doi: 10.1046/j.1468-2982.2002.00310.x, indexed in Pubmed: 11993614.

39. Lee $M$, Lineberry $K$, Reed $D$, et al. The role of the third occipital nerve in surgical treatment of occipital migraine headaches. J Plast Reconstr Aesthet Surg. 2013; 66(10): 1335-1339, doi: 10.1016/j.bjps.2013.05.023, indexed in Pubmed: 23735289.
40. Levy D, Strassman AM. Mechanical response properties of $A$ and $C$ primary afferent neurons innervating the rat intracranial dura. J Neurophysiol. 2002; 88(6): 3021-3031, doi: 10.1152/jn.00029.2002, indexed in Pubmed: 12466427.

41. Levy D. Endogenous mechanisms underlying the activation and sensitization of meningeal nociceptors: the role of immunovascular interactions and cortical spreading depression. Curr Pain Headache Rep. 2012; 16: 270-277.

42. Lim EC, Seet RC. Use of botulinum toxin in the neurology clinic. Nat Rev Neurol. 2010; 6(11): 624-636, doi: 10.1038/ nrneurol.2010.149, indexed in Pubmed: 21045798.

43. Lv X, Wu Z, Li Y. Innervation of the cerebral dura mater. Neuroradiol J. 2014; 27(3): 293-298, doi: 10.15274/NRJ2014-10052, indexed in Pubmed: 24976196.

44. Mahrhold S, Rummel A, Bigalke $H$, et al. The synaptic vesicle protein $2 \mathrm{C}$ mediates the uptake of botulinum neurotoxin A into phrenic nerves. FEBS Lett. 2006; 580(8): 2011-2014, doi: 10.1016/j.febslet.2006.02.074, indexed in Pubmed: 16545378.

45. Martin BC, Fagan PJ. The surgical therapy of certain occipital headaches. Plast Reconstr Surg. 1964; 33: 266-268, doi: 10.1097/00006534-196403000-00010, indexed in Pubmed: 14131623.

46. Melzack R, Wall PD. Pain mechanisms: a new theory. Science. 1965; 150(3699): 971-979, doi: 10.1126/science.150.3699.971, indexed in Pubmed: 5320816.

47. Mollendorff W. Ueber Hemikranie. Arch Pathol. 1967; 41: 385-395.

48. Moskowitz MA. Neurogenic inflammation in the pathophysiology and treatment of migraine. Neurology. 1993; 43: S16-S20.

49. Mosser SW, Guyuron B, Janis JE, et al. The anatomy of the greater occipital nerve: implications for the etiology of migraine headaches. Plast Reconstr Surg. 2004; 113(2): 693-7; discussion 698, doi: 10.1097/01. PRS.0000101502.22727.5D, indexed in Pubmed: 14758238.

50. Nabeshima S, Reese TS, Landis DM, et al. Junctions in the meninges and marginal glia. J Comp Neurol. 1975; 164(2): 127-169, doi: 10.1002/cne.901640202, indexed in Pubmed: 810497.

51. Noseda R, Melo-Carrillo A, Nir RR, et al. Non-Trigeminal nociceptive innervation of the posterior dura: implications to occipital headache. J Neurosci. 2019; 39(10): 1867-1880, doi: 10.1523/JNEUROSCI.2153-18.2018, indexed in Pubmed: 30622169.

52. Obach TJ, Planas JM, Puig PR. Increase in PGE2 and TXA2 in the saliva of common migraine patients. Action of calcium channel blockers. Headache. 1989; 29(8): 498-501, doi: 10.1111/j.1526-4610.1989.hed2908498.x.

53. Oh MY, Ortega J, Bellotte JB, et al. Peripheral nerve stimulation for the treatment of occipital neuralgia and transformed migraine using a c1-2-3 subcutaneous paddle style electrode: a technical report. Neuromodulation. 2004; 7(2): 103-112, doi: 10.1111/j.1094-7159.2004.04014.x, indexed in Pubmed: 22151191.

54. Olesen J, Burstein R, Ashina M, et al. Origin of pain in migraine: evidence for peripheral sensitisation. Lancet Neurol. 2009; 8(7): 679-690, doi: 10.1016/S14744422(09)70090-0, indexed in Pubmed: 19539239. 
55. Olesen J, Iversen HK, Thomsen LL. Nitric oxide supersensitivity: a possible molecular mechanism of migraine pain. Neuroreport. 1993; 4(8): 1027-1030, doi: 10.1097/00001756199308000-00008, indexed in Pubmed: 8241457.

56. Olesen J, Jansen-Olesen I. Nitric oxide mechanisms in migraine. Pathol Biol. 2000; 48: 648-657.

57. Ottosson A, Edvinsson L. Release of histamine from dural mast cells by substance $P$ and calcitonin gene-related peptide. Cephalalgia. 1997; 17(3): 166-174, doi: 10.1046/j.14682982.1997.1703166.x, indexed in Pubmed: 9170339.

58. Paemeleire K, Bartsch T. Occipital nerve stimulation for headache disorders. Neurotherapeutics. 2010; 7: 213-219.

59. Page P. Cervicogenic headaches: an evidence-led approach to clinical management. Int J Sports Phys Ther. 2011; 6(3): 254-266, indexed in Pubmed: 22034615.

60. Palmisani S, Al-Kaisy A, Arcioni R, et al. A six year retrospective review of occipital nerve stimulation practice--controversies and challenges of an emerging technique for treating refractory headache syndromes. J Headache Pain. 2013; 14: 67, doi: 10.1186/1129-2377-14-67, indexed in Pubmed: 23919570.

61. Patel N, Kirmi O. Anatomy and imaging of the normal meninges. Semin Ultrasound CT MR. 2009; 30(6): 559-564, doi: 10.1053/j. sult.2009.08.006, indexed in Pubmed: 20099639.

62. Penfield W, McNaughton F. Dural headache and innervation of the dura mater. Arch Neurol Psychiatry. 1940; 44(1): 43, doi: 10.1001/archneurpsyc. 1940.02280070051003.

63. Perry CJ, Blake $P$, Buettner $C$, et al. Upregulation of inflammatory gene transcripts in periosteum of chronic migraineurs: Implications for extracranial origin of headache. Ann Neurol. 2016; 79(6): 1000-1013, doi: 10.1002/ ana.24665, indexed in Pubmed: 27091721.

64. Pickett A. Re-engineering clostridial neurotoxins for the treatment of chronic pain: current status and future prospects. BioDrugs. 2010; 24(3): 173-182, doi: 10.2165/11534510000000000-00000, indexed in Pubmed: 20462283.

65. Popeney CA, Aló KM. Peripheral neurostimulation for the treatment of chronic, disabling transformed migraine. Headache. 2003; 43(4): 369-375, doi: 10.1046/j.15264610.2003.03072.x, indexed in Pubmed: 12656708.

66. Purkiss J, Welch M, Doward S, et al. Capsaicin-stimulated release of substance $P$ from cultured dorsal root ganglion neurons: involvement of two distinct mechanisms. Biochem Pharmacol. 2000; 59(11): 1403-1406, doi: 10.1016/ s0006-2952(00)00260-4, indexed in Pubmed: 10751549.

67. Rapidis AD. The therapeutic result of excision of the superficial temporal artery in atypical migraine. J Maxillofac Surg. 1976; 4(3): 182-188, doi: 10.1016/s03010503(76)80029-x, indexed in Pubmed: 1066419.

68. Rennie C, Haffajee MR, Ebrahim MAA. The sinuvertebral nerves at the craniovertebral junction: a microdissection study. Clin Anat. 2013; 26(3): 357-366, doi: 10.1002/ ca.22105, indexed in Pubmed: 22806929.

69. Rifat SF, Moeller JL. Diagnosis and management of headache in the weight-lifting athlete. Curr Sports Med Rep. 2003; 2(5): 272-275, doi: 10.1249/00149619-20031000000008, indexed in Pubmed: 12959709.

70. Rummel $A$. The long journey of botulinum neurotoxins into the synapse. Toxicon. 2015; 107(Pt A): 9-24, doi: 10.1016/j. toxicon.2015.09.009, indexed in Pubmed: 26363288.
71. Sanniec K, Borsting E, Amirlak B. Decompression-Avulsion of the auriculotemporal nerve for treatment of migraines and chronic headaches. Plast Reconstr Surg Glob Open. 2016; 4(4): e678, doi: 10.1097/GOX.0000000000000663, indexed in Pubmed: 27200240.

72. Schueler M, Messlinger K, Dux M, et al. Extracranial projections of meningeal afferents and their impact on meningeal nociception and headache. Pain. 2013; 154(9): 1622-1631, doi: 10.1016/j.pain.2013.04.040, indexed in Pubmed: 23707274.

73. Schueler M, Neuhuber WL, De Col R, et al. Innervation of rat and human dura mater and pericranial tissues in the parieto-temporal region by meningeal afferents. Headache. 2014; 54(6): 996-1009, doi: 10.1111/head.12371, indexed in Pubmed: 24673461.

74. Shevel E. A new minimally invasive technique for cauterizing the maxillary artery and its application in the treatment of cluster headache. J Oral Maxillofac Surg. 2013; 71(4): 677-681, doi: 10.1016/j.joms.2012.12.001, indexed in Pubmed: 23507321.

75. Sjaastad O, Fredriksen TA. Cervicogenic headache: criteria, classification and epidemiology. Clin Exp Rheumatol. 2000; 18(2 Suppl 19): S3-S6, indexed in Pubmed: 10824278.

76. Struffert T. [Anatomy and malformations of the posterior cranial fossa]. Radiologe. 2016; 56(11): 960-966, doi: 10.1007/ s00117-016-0174-y, indexed in Pubmed: 27738723.

77. Tepper SJ. History and review of anti-Calcitonin gene-related peptide (CGRP) therapies: from translational research to treatment. Headache. 2018; 58(Suppl 3): 238-275, doi: 10.1111/head.13379, indexed in Pubmed: 30242830.

78. Treleaven J, Jull G, Atkinson L. Cervical musculoskeletal dysfunction in post-concussional headache. Cephalalgia. 1994; 14(4): 273-279, doi: 10.1046/j.14682982.1994.1404273.x, indexed in Pubmed: 7954756.

79. Uebner M, Carr RW, Messlinger K, et al. Activity-dependent sensory signal processing in mechanically responsive slowly conducting meningeal afferents. J Neurophysiol. 2014; 112(12): 3077-3085, doi: 10.1152/jn.00243.2014, indexed in Pubmed: 25253472.

80. Wall PD. The gate control theory of pain mechanisms. Are-examination and re-statement. Brain. 1978; 101(1): 1-18, doi: 10.1093/brain/101.1.1, indexed in Pubmed: 205314.

81. Welch MJ, Purkiss JR, Foster KA. Sensitivity of embryonic rat dorsal root ganglia neurons to Clostridium botulinum neurotoxins. Toxicon. 2000; 38(2): 245-258, doi: 10.1016/ s0041-0101(99)00153-1, indexed in Pubmed: 10665805.

82. Weiner RL, Reed KL. Peripheral neurostimulation for control of intractable occipital neuralgia. Neuromodulation. 1999; 2(3): 217-221, doi: 10.1046/j.1525-1403.1999.00217.x, indexed in Pubmed: 22151211.

83. Yegutkin GG, Guerrero-Toro C, Kilinc E, et al. Nucleotide homeostasis and purinergic nociceptive signaling in rat meninges in migraine-like conditions. Purinergic Signal. 2016; 12(3): 561-574, doi: 10.1007/s11302-016-9521-8, indexed in Pubmed: 27369815.

84. Zakharov A, Vitale C, Kilinc E, et al. Hunting for origins of migraine pain: cluster analysis of spontaneous and capsaicin-induced firing in meningeal trigeminal nerve fibers. Front Cell Neurosci. 2015; 9: 287, doi: 10.3389/ fncel.2015.00287, indexed in Pubmed: 26283923. 